\title{
A Reaction (not a Response) to Starke's Paper
}

\author{
Stephen R. Anderson \\ Yale University \\ sra@yale.edu
}

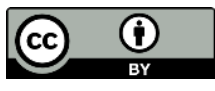

How to cite: Anderson, Stephen R. 2021. A Reaction (not a Response) to Starke's Paper. Isogloss. Open Journal of Romance Linguistics 7, 13: 1-2.

I was unhappy to see that Starke's paper, to which we are invited to reply, is actually an unedited video of a conference talk: I'm an old guy, and I read papers, but I avoid videos. However, I did watch most of this one, and I have to say that I cannot possibly provide a substantive response to it. The speaker (together with NELS audiences more generally, perhaps) assumes a view of syntax, morphology and their inter-relation which is hopelessly far from anything I can connect with. The massively ramified tree structures with which he deals do not resemble anything in my experience of the verbal morphology of any Romance language with which I am familiar (as surveyed, for instance, in Maiden 2018), and the general absence of connection with the literature on Romance or morphological theory (apart from his own views) is somewhat daunting.

The operations he performs on these trees remind me in many instances of a principle attributed by the German Sanskritist Franz Kielhorn (1887) to Kātyāyana in his commentary on Pānini: roughly, when there are two rules, and the results are different depending on the order in which they are applied, apply the rules in such a way as to produce the correct form. This a very useful and powerful principle, but one in whose scientific status I have little confidence.

Overall, then, I'm afraid I cannot relate to this paper nearly well enough to produce a coherent reply. I am reminded of Morris Halle's comment once on the proposals of my thesis: "you may be right, but if you are, I'm too old to change the way I look at things enough to do phonology that way" (or words to that effect). 
Morris was only about 50 at the time, and many theoretical revisions still lay in the future of his long career, but I get the point. I have recently revised my book on the history of phonology (Anderson, 2021) to reflect advances in our knowledge of history since 1985 , and that has given me occasion to contemplate the many instances in which older generations just couldn't relate to the new stuff. In some cases, they were probably quite right not to do so, and in many others quite wrong. But when I find that I just cannot get inside Starke's Weltanschauung, I know that I'm not the first to have that kind of experience. Whether my failure to relate to Nanosyntax in Cinemascope is misguided or not, only time will tell.

The governing thesis that morphological irregularity is generally illusory, and can always be reduced to regularity, reminds me of an article that should be read more widely than it is (for cautionary reasons): James Foley's (1965) "Prothesis in the Latin Verb sum". Foley argues that the paradigm of sum can be derived from a single root $/ \mathrm{s} /$, regular endings and a set of phonological rules. Now a number of those rules happen to be formulated in such a way that they couldn't ever apply to anything except forms built from the root $/ \mathrm{s} /$, but still, he does get the entire paradigm as "regular". Much of what we do as linguists is of course a search for order and coherence in what seems arbitrary, but we need to exercise some care when we do so not to exaggerate Nature's sense of orderliness.

\section{References}

Anderson, Stephen R. 2021. Phonology in the Twentieth Century. $2^{\text {nd }}$ edition, revised and expanded. Berlin: Language Science Press.

Foley, James. 1965. Prothesis in the Latin Verb sum. Language 41:59-64. https://doi.org/10.2307/411851

Kielhorn, Franz. 1887. Some Devices of Indian Grammarians. Indian Antiquary 16:244-252. [reprinted in J. F. Staal (ed.). 1972. A Reader on the Sanskrit Grammarians, 123-134. Cambridge, MA: MIT Press]

Maiden, Martin. 2018. The Romance Verb. Oxford: Oxford University Press. 